\title{
Some Problems of
}

\section{Scientific Book Publication*}

Mr. Benjamin is president, $M_{c} G r a w-$ Hill Book Company, Inc.

$\mathrm{W}$

HEN I was asked to take part in this program on the theme "Problems of Scientific Publication," I accepted readily, for, frankly, I felt I was just the man. I say this because the scientific book publisher nowadays is full of problems, and having a weakness for the spoken as well as the written word, he likes to talk about his problems. Indeed, many a book publisher is like one of A. P. Herbert's fellow Members of Parliament about whom Mr. Herbert remarked, "He is the kind of man who can always be depended upon to find a problem to every solution."

Today, we publishers of scientific books find that most of our problems, and most of the problems to the proposed solutions to these problems, are economic ones. They involve rapidly mounting production costs, and failure or inability to adjust prices to meet these costs. Also, they involve the phenomenon of increasing scientific specialization, under which markets for specialized books have remained relatively small in spite of the tremendous growth in the total field of science and the total numbers of writers and buyers of scientific books. Also involved is a distressing lack of technological improvement in methods and machines for type composition, especially for composition of mathematical, chemical, and other symbolic scientific matter.

\footnotetext{
"Paper presented at meeting of Pure and Applied Sciences Section, ACRI, New York City, July 3, 1952.
}

I should not take your time this morning for a discussion of these dismal economic problems, for I could only repeat what I said in an article published in a recent issue of Physics Today. If you are interested in these economic and technical matters, you can read this article in a few minutes. But before you do so, I should perhaps help you to evaluate it by quoting from a paper of one of your distinguished colleagues, Dr. Vernon Tate:

In the April number of Physics Today, Mr. Curtis Benjamin, President of McGraw-Hill, published an interesting and provocative article entitled, 'What Price Scientific Books?' An abstract of the paper states, 'Many specialized scientific books which should be published for the general good of science cannot be accepted for publication because of high printing costs and their limited audiences. What is needed is a research program carried out by the publishers themselves that will aim at reduced costs and increased speed in printing scientific material.' Mr. Benjamin's argument is well phrased, shrewdly designed, interestingly presented and completely fallacious.

Of course, my face was inappropriately red at Dartmouth when your colleague finished this evaluation. I soon recovered, however, when Dr. Tate read on and I discovered that he thought my argument was fallacious because necessity, the urgent necessity of science, would surely find a way to solve these problems which have bothered me and other publishers of scientific books for several years. Dr. Tate says:

Any needed scientific or technical book or communication can be published today in an 
edition sufficiently small to meet the needs of the field and at costs that are within the realm of possibility. Please note the emphasis on the word published. If the break-even point for a conventional book is 8,00o copies, and the market will absorb only half of these at current rates, including a fair profit for the entrepreneur, then a conventional book is not what is needed, or perhaps conventional channels of publication are not adequate. If author, publisher, librarian and user cannot convince themselves of this elemental fact, we are indeed due for trouble.

Now, frankly, I in turn was not convinced by Dr. 'Tate's argument and assurance. Maybe you would be both convinced and comforted by his article.

Now, I want to turn next to a publishing problem which might be discussed under the heading "The Rising Tide."

In recent years I have heard librarians, and many scientists, too, rail against the rapidly rising tide of scientific literature. Indeed, there is a general tendency to deplore the volume and berate the density of this tide. Many people, including librarians, have thrown up their hands and exclaimed, "This is a senseless and wholly unmanageable flood. How can we expect to cope with it? Something must be done to stop it, or at least to check it, or maybe to channel it in a different direction, or something...."

This is, I think, an unrealistic and unreasoned attitude. The tide of scientific literature in America is neither higher nor stronger than the tide of science itself. In deed, the tide of literature has lagged behind the rising tide of science. The fullest flood of books, monographs, reports, symposia, pamphlets, articles, indexes, digests, and abstracts is yet to come. None of us should waste any time in deploring and berating. We should bend all our efforts to coping.

Whenever and wherever this problem has been discussed, there always has been much talk of the evils of duplication in scientific literature. Many people seem to be convinced that duplication is an unnecessary evil, and that if this great evil could somehow be eliminated, the problem of publishing, cataloging, housing and using scientific literature would be easier to solve.

While the great waste of time, effort, and expense is readily evident in the seemingly pointless duplication of publications in almost every field of science, I cannot join those who sadly deplore this situation and strongly feel that something must be done about it. The problem is obvious: Who will do the eliminating of the offending publications? What man, or what group of men, is so wise as to say generally, "We already have enough publications on this subject. No more should be produced." Or, more specifically, who is so wise, or so sure of himself, as to say to an ambitious young scientist, or even to an energetic older one, "Look here, young man (or old fellow), many of your peers and superiors already have written good books in this field. You must not indulge yourself in the wasteful effort of trying to write another."

While there usually is no direct correlation between the quality and the quantity of publications in a given field of science, I am sure that, in the long run, the quality would suffer if the quantity were arbitrarily rather than naturally restricted. In the administration of justice it is generally agreed that it is better that ten guilty men should go free than one innocent man should suffer unjustly. For my part, I would rather encourage ten, or even twenty, seemingly pedestrian authors than to risk the discouragement of one who might make a genuine and original contribution to his field. Indeed, it seems to me that the great advances in scientific literature have been made by striking individual mutations rather 
than by systematic stages of evolutionary progression.

I have just spoken of the natural restriction of scientific publications. By this I mean the kind of restriction that prevents the publication of many manuscripts in the free competition of normal commercial publication. As I indicated earlier, economics is a large restrictive factor. Unhappily this factor operates most decisively against advanced and specialized publications which are likely to be of the most value in advancing the front of science. Many scientific books cannot be published because markets are too small and production costs are too high. (In this connection it is interesting to note another curious phenomenon: more often than not there is a startling inverse ratio between the size of the potential market for a scientific book and the size of the printer's bill. The most highly specialized scientific publications usually contain the largest amounts of complicated mathematical or chemical matter, and hence are the most costly to produce. This vexing phenomenon does not operate in the publication of monographs and specialized treatises in the humanities and social sciences, which may explain why so many university presses stick pretty closely to highbrow books in those fields.)

Two other restrictive factors in the natural selection of scientific books are (I) lack of technical accuracy and originality, and (2) lack of literary competence, not to say elegance. Fortunately, these two factors operate most decisively against textbooks and general treatises at the elementary and intermediate levels.

Recently a well-known librarian read a brilliant paper which revealed his deep concern over the enormous volume of current scientific literature, the copious duplication of titles, and the onerous job which faces the librarian in trying to separate "the froth from the substance." I wondered then, as I often have before, whether librarians in general realize how deep is their debt to book publishers for assistance in this onerous separation process. Well, I can give you a rough idea. The firm with which I am connected publishes about 300 new and revised books a year. This number is selected from a list of about 2700 published titles and an annual offering of 5000 to 6000 new manuscripts. Now, I realize that our 300 titles in any year contain quite a bit of froth, and I know that we reject each year much real substancewhich is, of course, quickly snapped up by our more astute competitors. I hope, however, that this rough indication of one publisher's ratio of separation will give you both comfort and courage in your own battle against the rapidly rising tide.

One further observation in this connection which may give you additional comfort: scientific literature is wholly free of "vanity" publishing. You do not have to cope with the numerous author-financed volumes which are published each year in poetry, in the polite letters, and in the unpolite controversial areas of economics and politics. For this you should, perhaps, thank the scientists more than the publishers. As a rule, scientists are both fiercely proud and moderately poor.

Another problem faced by the publisher of scientific books has a direct relation to Dr. Sunderlin's interesting and informative discussion of the National Research Foundation. This problem is posed by the flight of scientists, and hence of potential authors of scientific books, to government research agencies. Facts and figures on the extent of this flight have been widely published in recent months; I am sure they are well known to most of you. Proportionately more scientists are now working, either directly or indirectly, for the federal gov- 
ernment than there were at the height of World War II, and, we are told that the new peak has not yet come.

A measure of the rapid growth in this new peak can be found in the following figures which were recently published by the National Research Council. Total federal expenditure for research at the height of the World $\cdot$ War II program in 1945 was $\$ 880$ million. By 1950 this expense had climbed to $\$ \mathrm{I}, 040$ million. It was $\$ \mathrm{I}, 3$ I 0 million in I $95 \mathrm{I}$, and is estimated to be $\$ \mathrm{I}, 640$ million this year, with a substantial increase ahead for next year.

Further it is estimated that $56 \%$ of the total research in the country is now financed, either directly or indirectly, by the federal government, and this figure is expected to increase to $70 \%$ or $75 \%$ within the next few years. This means, of course, that $70 \%$ or $75 \%$ of the country's scientists will be working for the governmentor this should be the proportion if the government is getting a proper return of brain power for its dollar expenditure. What's more, this $70 \%$ or $75 \%$ will include most of the ablest scientists in the land. Patriotic and financial considerations will insure this - and this is, of course, as it should be.

Now, just how does this flight affect commercial publication of scientific books? The answer is rather obvious: it takes large numbers of top scientists off the market, so to speak, as far as private authorship is concerned. The reason for this is to be found in an antiquated public law, Section I I I of Title 44, U.S. Code, which was enacted many years ago and which has since been amended in many minor respects but never thoroughly overhauled and modernized to meet modern conditions and requirements. As all of you know, this law requires that all printing for government agencies (other than the Supreme Court and the National Science Foundation), or for private agen- cies operating with government funds, must be done by the Government Printing Office, or under a hard-to-come-by waiver from the G.P.O. or the Joint Congressional Committee on Printing. It follows that under this law, all the results of research done by the thousands of governmentemployed scientists must be published or printed (most government agencies make no distinction between these two functions) by the G.P.O. This monopoly-and to my way of thinking it is one of the world's largest and most effective monopolies-has cancelled in each recent year a higher proportion of the publisher's normal source of scientific manuscripts.

Now, before I pursue this point further, I want to comment briefly on Title 44 of the U.S. Code and on the administration of the G.P.O. under its authority-and I hope you will pardon my obvious prejudice if I sound a bit caustic.

First, I think the law is unreasonable and discriminatory in its designation of printing as the only commodity or service which one government agency must buy from another government agency. The executive and military departments of the government can buy anything and everything under the sun except printing. The Navy, for example, can buy anything from a battleship or a super-bomber down to hairnets, fish hooks, and toothpicks-but it cannot buy printing, not without a waiver under the strictest interpretation of the law.

Second, this law embarrasses and handicaps operating officials in almost every executive and military department of the government. They hate its restrictive and delaying influence on their operations, but they dare not oppose it, or even to cry out against it. The G.P.O. is run by a powerful Joint Committee of Congress, and appropriations for the executive and military departments come from Congress. 
Third, the administration of the G.P.O., under this law, permits widespread petty patronage and substantial waste of public funds. Not many years ago Congressmen gave away packages of seeds-now they give away nicely bound books. ('The voluminous and costly yearbook of the Department of Agriculture is a favorite item to gladden a voter's heart.) The amount of waste resulting from overprints that are produced for sale by the Superintendent of Documents, if it could be accurately reported, would upset taxpayers throughout the land. I know of no recent figures on this, but as some of you remember, LeRoy Charles Merritt, in his The United States Government as Publisher (University of Chicago Press, I 943), reported that in 1940 only $14 \frac{1}{2} \%$ of the copies printed for this purpose were sold. James L. McCamy, in his admirable Government Publications for the Citizen (Columbia University Press, 1949), reported that in the fiscal year 1947 , sales income compensated for only $14 \%$ of the cost of government publications produced for sale by the Superintendent of Documents in that year. (I hope you will please understand that in citing these figures, I am not blaming the Public Printer. $\mathrm{He}$ is an experienced man who knows his business. Nor am I blaming the Superintendent of Documents. $\mathrm{He}$ is a bright, energetic young man who seems to be giving his best effort to his job. I do blame the law, the organizational system, the administrative policies, and the political traditions under which these men have to operate.)

Now, as suggested earlier, Title 44 does provide exemption under which official documents, scientific and otherwise, may be published by private firms. The law exempts quite specifically "such classes of work as shall be deemed by the Joint Committee on Printing to be urgent or necessary to have done elsewhere," and which presumedly should be done elsewhere in the interest of the public good.

The trouble here is that the administration of the law has been so rigorous as to permit very few exceptions in recent years. Most of the exceptions which have been permitted have come in wartime (that is "official" wartime, not "police-action" wartime) and under great pressures or quasilegal devices.

I strongly feel that this law needs fundamental revision in order to permit the executive or military departments to contract with commercial firms for production and distribution of many government publications which can and should stand on their own feet financially. Until this can be done, the Joint Committee's regulation of printing under the present law should be relaxed to permit more exemption "for the public good." It goes without saying that this should be done with the usual safeguards against abuses.

There are many arguments-involving matters of law, private rights, and public morals-for and against this proposed legal reform. I shall not attempt to give them even a lightly-once-over treatment here, but I should like to indicate some of the advantages which would accrue from reform, primarily to scientific literature, secondarily to commercial publishers of the same, and tertiarily to the taxpayer. (I place the publisher in a secondary position because he is also a taxpayer, and hence any reform would compound his benefit.)

First, if allowed to do so, commercial publishers could help materially in relieving some of the great pressure for quicker publication of unclassified government research. As entrepreneurs, we could not, of course, publish primary research reports in great numbers, but now and then such reports can be made to support themselves 
commercially. We could, however, publish commercially vast quantities of secondary reports and other literary by-products of government research. I refer to such materials as the M.I.T. Radiation Laboratory Series, the A.E.C.'s National Nuclear Energy Series, the Rand Corporation Series, and other similar projects which we at McGraw-Hill have undertaken at our own expense. I refer also to such volumes as the famous Smythe Report, which was published so successfully by the Princeton University Press, and the more recent Glasstone Source Book of Atomic Energy, published so successfully by the D. Van Nostrand Company.

If commercial publishers were permitted to produce many more official publications such as these, this would allow the government research agencies and the G.P.O. to devote proportionately more of their time, funds, and production capacity to the publication of primary research, both classified and unclassified.

Second, and almost equally important to all of us as taxpayers, commercial publication of self-supporting scientific and technical documents of government origin would save annually thousands upon thousands of dollars of federal funds. I hope you will pardon me if I again refer to the Radiation Laboratory Series as an example of what can be done in this direction. At a rough estimate, the government has a net saving of approximately $\$ 260,000$ in the avoidance of the production cost of these 27 volumes as official technical reports-reports which were required of M.I.T. under their O.S.R.D. contract. This figure represents the estimated cost of composing, printing, and binding 500 copies of each volume as an official technical report, which would have been done normally at government expense. The publisher assumed all this manufacturing cost and in addition has paid over \$1 20,000 into the U.S. Treasury as royalty on sales to date. Thus the commercial publication of this series alone already has given the U.S. Treasury-and the U.S. taxpayer - a total benefit of $\$ 380,000$. Add to this sum the amount of tax paid by the publisher on his profit from sales of these official reports, and add also the anticipated royalty for the next few years, and one would be rather safe in estimating that, in the end, the total benefit to the U.S. Treasury will be well over onehalf million dollars. Of course this particular performance could seldom be matched, but with the present legal and regulatory restrictions removed, scores of smaller publications might more than match this saving annually.

Now, I have only sketched this problem in its broadest outlines. You may be sure that we publishers are pressing our arguments on our, and your, public servants in Washington. Of course, we have been accused of having special interests, and naturally we have been the first to admit the obvious truth of this charge. I hope that you-all of you librarians-will feel that you, too, have special interests in this problem, and that you will see fit to support our arguments whenever and wherever an opportunity presents itself. 


\section{Proposed Statement of Principles to Guide Large Scale Acquisition and Preservation of Library Materials on Microfilm}

\section{Introductory Note}

$\mathrm{T}$ His STATEMENT of principles was prepared by the Cooperative Committee on Microfilm Projects, a subcommittee of the Board on Resources of American Libraries, which was created by the board in 1950 in response to a need for long-range planning to save valuable manuscript and printed records in danger of loss through physical deterioration or the ravages of war. Members of the committee are: Ralph Carruthers, New York Public Library; Donald Coney, University of California; John Cronin, Library of Congress; Herman Fussler, University of Chicago; Lawrence Kipp, Harvard University; Charles Mixer, Columbia University; and B. E. Powell, Duke University (chairman). Robert B. Downs, University of Illinois, was the committee's first chairman.

The committee agreed at the outset that its first efforts should be devoted to outlining the scope of the job of recovery and preservation, and to the preparation of a statement of principles by means of which libraries and librarians might be aided in the selecton and mcrofilming of research materials. This is the statement. It suggests some of the areas in which microfilming programs are urgently needed and sets down conditions which must exist if a comprehensive program is to yield maximum results.

While the statement was in preparation, the committee decided to select a specific body of materials which everyone recognized as important and concentrate on the development of a program to preserve it. United States newspapers of the woodpulp period (since I 870) were chosen. Representatives in each of the 48 states were appointed to direct selection of the state's most important papers not already filmed. Lists were received from most of the states and have been published by the Library of Congress. Copies have been distributed to state library associations, historical societies, and other state agencies, with an appeal that they cooperate in filming and in stimulating the filming of their state papers appearing on the list. The Committee hopes that each state will be responsible for filming its papers, and that the state agencies acquiring copies will make them available for loan. In this manner, unnecessary multiplication of positive copies can be avoided and all available funds utilized to extend the copying program. Anyone interested in assisting with this program may secure additional information from the president of his state library association, or from members of the Committee.

The Committee will keep its eye on the newspaper project, but will turn most of its attention from now on to the copying of other materials in immediate need of preservation. -B. E. Powell, chairman, Committee on Cooperative Microfilm Projects.

\section{Statement}

The modern hazards of war are such that civilization risks the total loss of valuable manuscript collections unless a coordinated effort can be made to reproduce important manuscript collections and locate the copies at points far distant from the originals. One may then hope that either the originals or the copies will survive. Substantial bodies of printed materials are exposed to the same dangers. But some of these printed materials, particularly domestic and foreign newspapers of the woodpulp period, disintegrating periodicals, and out-of-print books face even more certain destruction through physical deterioration. Some progress has been made in conserving these materials through uncoordinated microfilming projects which have resulted in the deposit of copies of large numbers of manuscripts and extensive series in collections located in Europe and elsewhere. Microfilming efforts are also under way to preserve many of the outstanding domestic and foreign newspapers. And limited projects have been instituted to film early American and English periodicals. But any filming program dependent exclusively upon random selection and chance opportunities is likely to lead to the dissipation of available financial resources without a commensurate increase in either general security or accessibility. If this vast wealth of research material is to be salvaged and made accessible a more systematic attack on a larger scale is essential. 


\section{Preservation of Library Materials}

Perhaps the most pressing needs to which inter-library cooperation in microfilm projects would contribute relate to the preservation of library materials, specifically, and in descending order of priority, to the preservation of (I) domestic newspapers of the woodpulp period, (2) disintegrating periodicals, and (3) out-of-print books. In each of these fields there have been beginnings, commercial or otherwise. Indeed, in the field of newspaper microfilming vigorous programs are under way in several states where numerous papers have been and are being filmed by various libraries, commercial microfilming agencies and publishers. However, despite the relatively high interest and activity in this field, there is need for further planning which will augment current activity and resources and will induce a greater number of libraries, associations and other organizations which are interested in the preservation of the record of our civilization to assume a share of the responsibility for that preservation. ${ }^{1}$

Toward this end, this committee is endeavoring to secure from each of the fortyeight states appropriate lists of the newspapers (metropolitan, weekly, county, labor, foreign language, Negro, etc.) which have been microfilmed and of others to whose preservation highest priority should be given. The Committee is also endeavoring to stimulate particular libraries which have an interest in specific newspapers to undertake responsibility for filming them. Even with this effort, however, it seems unlikely that available resources will suffice for a fully satisfactory rescue operation in the field of domestic newspapers.

Nevertheless, plans for preserving domestic periodicals ought not to be postponed until newspaper programs are well launched. To be sure, the number of domestic periodicals which are rapidly deteriorating is far smaller than the number of deteriorating newspapers

1 The immensity of the newspaper problem is re flected in the holdings of the Library of Congress in igth and 20 th century woodpulp newspapers which total over 67,000 bound volumes. To microfilm these would require over $6 \%, 000,000$ exposures at a cost of roughly $\$ 2,000,000$ for a negative and positive print. Even if the newspaper preservation program were to limit itself during the forseeable future to the filmin of I gth century domestic newspapers, the resources of the Library of Congress would suffice only for a fraction of the total work to be done. On its own, the Li brary can undertake only the filming of certain large brary can undertake only the filming of certain large metropolitan dailies whose existence has been of maior
consequence as sources for our national history. The preservation of other papers must be left to the conscience and enterprise of the research libraries with strong interest in their regions, to the state and local libraries and the historical societies. not only because of the better quality of the paper on which they have been printed but also because the greater convenience of their format more adequately protects them. Nevertheless, there are titles among the domestic periodicals which should receive prompt attention or shortly there will be no extant copies suitable for filming. ${ }^{2}$ Lists should be compiled of foreign newspapers and of domestic and foreign periodicals urgently in need of salvage operations and priorities for their microfilming established.

It must be recognized that the problem of physical deterioration of woodpulp books and periodicals is now with libraries permanently. Long range plans for alleviating the situation must therefore be adaptable to incorporation into the regular fabric of the library economy. The even greater problem of preservation of foreign materials is covered implicitly in the following section on large scale acquisitions programs.

\section{Large-Scale Acqusitions Programs}

The Committeeshares with the Library of Congress a conviction that it is important that there be a planned program for copying large bodies of source materials in the countries of Western Europe and other parts of the world, as described in the following paragraphs, and hopes that many of America's research libraries will find it possible to participate in such a program.

The national microfilming program should be comprehensive and developed in detail as to method, type of operation, spheres of influence, priorities, and similar matters. It likewise should be flexible enough to permit alteration in nature, scope, duration, etc., without disrupting the basic structure of the program. Beginning with a statement of objectives this plan should progress through a survey of information and an analysis of all known factors, and conclude with a recommendation for action. ${ }^{3}$

2 Recently, the University of Kentucky Library circulated a list of most frequently cited periodicals and inquired into the the interest of research libraries in subscriptions for them in various forms of reproduction. I'his commendable type of activity should be expanded on a planned basis. It relates to acquisitions as well as to preservation.

3 The Library of Congress has taken systematic measures which are preliminary to a planned program for copying large bodies of source materials in Western Europe. This action has resulted from the conviction that a primary requirement of American scholarship is ready access to information concerning the collections of materials, published or unpublished, in the libraries, archives and similar institutions of Europe. In 1950 the Library sent a member of its staff to Paris as the base from which to embark upon the major assignments 
Despite any planned program to acquire research materials in microfilm form there will be other favorable opportunities to obtain valuable source materials at moderate cost through cooperation with organizations whose activities abroad permit including microfilming projects without normal overhead expenditure, e.g., the Library of Congress projects on Mt. Sinai and in Jerusalem. Additionally, particular opportunities to perform "rescue operations" by filming bodies of important materials which are likely to be destroyed or closed indefinitely to western scholarship will merit serious consideration as they occur. It is clear, however, that any acquisitions program dependent exclusively upon such chance opportunities will exhaust the financial resources of American libraries on a miscellany of unrelated projects; and it is equally apparent that a world-wide program planned to bring to this country copies of all valuable source material which may be soon lost to us would require the expenditure of sums greatly in excess of the resources available to our libraries for such purposes.

\section{Action Needed by Research Libraries}

The urgency and scope of the problem are

of the mission; namely, the dissemination of the Library's philosophy of cooperation in ascertaining and sharing information, in acquiring and sharing ma terials significant for research; and the surveying of quantities of unpublished bibliographical tools in ar chives, libraries and similar institutions with a view to future microfilming projects. Correlative assignments were the compilation of data on microfilming facilities and on the accessibility of materials for examination and for copying.

In the execution of these assignments the Library's representative established liaison with the Division of Libraries at Unesco; acquainted himself with the survey of information on microfilm equipment which was being conducted by Unesco and with the survey of facilities which was being compiled by the International Federation for Documentation in addition to making independent inquiries; spoke briefly at several international conferences and at a meeting of archivists and special librarians; called upon the directors of more than 100 institutions in Austria, Belgium, England, France, Germany, The Netherlands, Scotland, and Switzerland in order to gather at first hand essential information on the existing unpublished bibliographies, guides to collections, inventories, calendars, indexes and similar means of access to information; recommended priorities for suggested copying projects; and, finally, placed an extensive order at the Archives Nationales in

Paris. The result of the survey is embodied in a publication entitled Unpublished Bibliographical Tools in Certain Archives and Libraries of Europe: $A$ Partial List which the Library of Congress issued in October, I 952 and which has been distributed to the major research libraries of the United States and which is available to others upon application. Libraries will be encouraged to allocate funds for filming those items of special interest to them. The Library of Congress is prepared to devote as much of its resources as obligations of higher priority will permit to the reproduction of those bibliographical aids. Active participation of other libraries will bring closer the day when the American scholar will have ready access to vast quantities of information hitherto available to him only at great cost and after considerable delays. outlined above. Research libraries are urged individually to take an active, continuous and systematic role in its solution through action as follows:

A. Adoption and adherence to the principles to govern microfilming activities and services set forth in this Statement.

B. Regular and continuing allocation of a portion of each year's book funds to microfilm projects. Research libraries should agree to purchase positive film copies of materials only when needed for continuous reference, using available funds primarily for making negative copies of printed and manuscript matter not hitherto filmed. (The percentage allocated need not be large, and regular use of from one to two percent of book budgets by each of the nation's research libraries will support sizeable expansion of microfilming activities.) Each library should select its projects first with its own needs in mind. A secondary consideration will be the requirements of national scholarship in general. Where no compelling local need dictates the project, the library can determine an appropriate annual one (or a longer-range project to be completed in annual installments) by:

( I) Consulting with the state representative of the Committee on Cooperative Microfilm Projects to select newspapers which need microfilming.

(2) Selecting one or more items from the Unpublished Bibliographical Tools in European libraries to be copied, or

(3) Consulting with the Library of Congress Union Catalog Division regarding cooperative projects under way or being planned by other libraries in which the library may participate.

C. Active participation with the Association of Research Libraries, the Library of Congress, state library associations, and other learned societies and associations in initiating and supporting requests for foundation and governmental grants to support microfilming projects aimed at preserving disintegrating research materials like those identified in this Statement or at bringing to this country in film form research materials which are not now available here.

\section{Principles}

Only through an organized cooperative program, backed by libraries and other institutions, can acquisition and preservation of the scope envisioned be accomplished. And under- 
lying any broad program of cooperation in which numerous libraries and agencies share the expense, work, and product of microfilming activity, there should be basic agreement on the technical standards which will obtain; on policy with respect to the pricing of positive copies of microfilm, in order to share equitably the cost of the program; and on the ready accessibility of microfilm for the use of scholars.

The Committee has agreed upon the following principles which should be followed if maximum effectiveness is to be achieved:

\section{Technical Standards}

Good technical standards are essential to any large scale microfilming project. A satisfactory set of tentative standards for microfilming newspapers has been prepared for the Association of Research Libraries. The Committee endorses its use. Standards to cover, in greater detail, this and other aspects of the microfilming program envisioned by this Committee are being prepared by the ALA Committee on Photoduplication and Multiple Copying Methods.

\section{Pricing}

On the assumption that it is reasonable for a library sharing access to material through owning a positive microfilm print to pay a share of the negative's cost, the Committee proposes the following principles on pricing:

(I) A library owning a master negative may include in the sale price of all positive prints to other libraries or to individuals whatever portion of the negative cost it considers necessary to equalize the cost of producing the microfilm copy. Once the markup for sale of positive prints from a master negative has been established, it will be continued for all subsequent sales so as not to inflict an inequity upon early purchasers or subscribers.

(2) The sale price to non-participating libraries or to individuals of positive prints from master negatives produced in the course of a cooperative project will be fixed by the cooperative agreement.

(3) An organization lending materials for microfilming by another library will not expect to receive in return a free positive or other compensation. (In case this is necessary in foreign microfilming, the cost will be considered as part of the negative cost.)
(4) Nothing in this section shall be construed as contravening the normal profit included in the price of microfilms established by any library.

\section{ACCESSIBILITY}

It is important that the results of the program be made as accessible as circumstances will permit. To this end the Committee recommends the following principles on access:

(I) Permission to read. Libraries should make microfilm as accessible as they would original materials of similar nature.

(2) Permission to copy original materials. The owning library should not impose limitations on the accessibility for reproduction of material in its collections unless the nature, status, or physical condition of the material makes copying inadvisable.

(3) Loan of microfilm. Any film, positive or negative, which can be replaced easily should be made available on interlibrary loan. The Committee approves and recommends to libraries the principles set forth in the report of the ARL Committee on Inter-Library Lending of Microfilm. ${ }^{4}$

(4) The reproduction of film copy. Although the owning library itself should not impose limitations on the accessibility of micro-

\section{(Continued on page 302)}

4 The Committee on the Inter-library Lending of Microfilm favors a liberal policy of microfilm lending. The principal provisions of such a policy are set forth below. It should be borne in mind that any one provision listed below is subject to limitations implied in the other provisions.

a. The conditions of loan set forth in the proposed (Approved by ALA Council, July I952) revision of the ALA Interlibrary Loan Code under Part I: Printhe ALA Interlibrary Loan Code under Part I: Prinlending of microfilm. Specific reference is made in Part I of the Code to the purpose, responsibilities, expenses, and duration of interlibrary loans.

b. Positive microfilm should be lent freely and without restriction.

c. Negative microfilm should be lent provided the lending library owns the original, or has easy access to the original for re-photographing, and provided the original is not so fragile that re-photographing would damage it. Extreme care should be exercised in han. dling negative microfilm.

d. Microfilm of manuscript material owned by another library should not be lent without the permission of that library except in instances where it is quite obvious such permission is unnecessary. The use of such material should be subject to the conditions imposed on the borrowing library by the report of the Committee on the Use of Manuscripts (Appendix B, p. 32, "Minutes of the 37 th Meeting of the ARL, Chicago, July $6-7$, I 95 I").

e. The requesting library is required to name in the first application for a loan of microfilm the type of microfilm reading equipment it has available for use. Microfilm should be restricted to use in the building where suitable equipment and supervision are availwhere suitable

$f$. The minimum unit of loan will be one reel. Not more than four reels should be requested at one time. (See also ARL "Minutes, January 26, 1952," appendix E, p. 59.) 
pleased his advice had not been taken. He wonders if it is yet time for standardization. When it is time, we do not want to fail to get standards, he stated. Our talking should be about standardizing reproduction, not machines, he added.

Donald Cameron (Rutgers): The more machines Rutgers has, the more expensive they become. As improvements arise, and new machines are purchased, he has tried without success to turn his old ones in. $\mathrm{He}$ believes that the time is too early for standardization.

$M r$. Clapp: He agreed that machines are bad. He points out that the subject under discussion is standardization of materials sizes. The standardization of film, as we have it, is owed to the film industry, and because of that standardization, it is possible to order usable film from Greece, for instance.

Today's talk is not about film, but "flats," transparencies and non-transparencies. Powers can produce flat film.

We should express preferences for one or more sizes. He thinks these preferences depend upon the filming equipment we have.

$M r$. Powers: He observed that roll, card and flat each has a place. It depends upon what it is for. He thinks sheets costly. He has no reader, except an experimental one, for flat prints. He can work on rolls more cheaply.

Mr. Boni: He suggested that sizes should be expressed in inches.

Ermine Stone (Sarah Lawrence): She asked if FID had done anything for standardization.

$M r$. Clapp: He said that the International Standards Organization is the standardization agency for Europe.

Morris Gelfand (Queens): He believes that a study is required. He does not favor too specific recommendations now. He wonders if the group present is the one to speak.

Mr. Clapp: This body, having been consulted as to its preference of the 8 sizes, can transmit to the American Standards Association its opinion as an expression of preference.

Charles F. Gosnell (New York State Library): He observed that the sizes Mr. Clapp suggested are good.

$M r$. West: He believed that if we want anything done, we should tell the ASA.

Fremont Rider (Wesleyan): He agreed with the anonymous writer that we should favor standardization, but he did not believe that it is the time for regulation of sizes. $\mathrm{He}$ thought the three sizes mentioned are far enough to go.

\section{Proposed Statement on Microfilm}

\section{(Continued from page 29I)}

film material in its own collections, manuscript and rare printed materials available on film should not be reproduced by one library for another without permission of the library owning the original materials.

\section{Microfilming Clearing House}

There has been established in the Union Catalog Division of the Library of Congress a Microfilming Clearing House, the purpose of which is to provide a central source of information on extensive microfilming projects planned, in progress, or completed. Much of the material here assembled is disseminated in the Microfilming Clearing House Bulletin which is published at irregular intervals as an appendix to the Library of Congress Information Bulletin. The quality and value of this service will depend on the cooperation of all who undertake extensive microfilming projects. Therefore, to prevent unnecessary duplication of effort, all institutions are urged to report their current and completed projects on the printed cards provided by the Library of Congress and to make inquiries before starting new projects. 